\section{Epidural Lumbar Block or Lumbar Plexus Block Combined with General Anesthesia: Efficacy And Hemodynamic Effects on Total Hip Arthroplasty}

Leonardo Teixeira Domingues Duarte, TSA, M.D.; Paulo Sérgio Siebra Beraldo, M.D.; Renato Ângelo Saraiva, TSA, M.D.

\section{INTRODUCTION}

Aging of the population is responsible for making total hip arthroplasty (THA) a common procedure, especially due to the greater prevalence of osteoarthrosis.

Advanced age and associated diseases in those patients represent a challenge for anesthesia and analgesia for THA. The increased stress imposed to the patient by the surgery is a great contribution for the higher incidence of cardiovascular and pulmonary complications. For this reason, the choice of anesthetic technique, which should be easy to execute, should decrease perioperative morbidity, and allow early patient ambulation is crucial $^{1,2}$.

Although different techniques are used in THA the best technique based on efficacy and safety has not been determined. General anesthesia, neuroaxis blockades, and peripheral nerve blocks (lumbar and sacral plexus blocks) represent the techniques used more often ${ }^{3}$. Each technique has different efficacy with vantages and disadvantages. Neuroaxis blocks are probably used more often among us due to the quality and predictability of the anesthetic blockade, low cost, and easiness to perform. However, those techniques are not devoid of risks ${ }^{4,5}$. Recently, lumbar plexus blocks for anesthesia and analgesia in THA have received more attention ${ }^{6,7}$. Excellent analgesia and limited motor and sympathetic blockades, without the adverse effects of local anesthetics and opioids administered in the neuroaxis, and the lower morbidity of hemorrhagic complications than neuroaxis blocks in patients treated with drugs that change coagulation parameters represent the main advantages of peripheral nerve blocks ${ }^{5,8}$.

The current clinical assay was designed to test the hypothesis that the effectivity of the nociceptive blockade promoted by posterior lumbar plexus block is similar to that of epidural lumbar block when combined with general anesthesia in patients undergoing THA. Besides assessing the efficacy of the blockade, secondary objectives included the comparison of both techniques regarding the technical difficulty of the blockade, hemodynamic effects, and influence on perioperative bleeding.

\section{METHODS}

This study was approved by the Ethics and Research Committee of the Rede Sarah de Hospitais de Reabilitação. After signing of the informed consent, consecutive patients with physical status ASA I to III scheduled for THA between March and September 2006 at the Hospital Sarah in Brasília, Brazil (a tertiary rehabilitation hospital), were included in the study. Patients were excluded from the random distribution if they refused to participate in the study; had peripheral neuropathies, coagulopathies, or hypersensitivity to drugs used for analgesia; infection at the site of puncture; spinal deformities or history of spinal surgery; and those scheduled for review of the hip.

Patients were randomly separated into two groups based on a computer-generated permutation table presented in sealed opaque envelopes. In the Epidural group patients received continuous epidural lumbar block, while in the Lumbar group patients underwent continuous posterior lumbar plexus block. Randomized allocation was performed in eight-patient groups, stratified according to the surgical approach (lateral or posterior). The anesthesiologist responsible for the case was informed of the group the patient belonged to only at the moment of the surgery and he did not have further participation in the study. One of three surgeons who perform this surgery at the hospital performed the arthroplasties.

Patients were premedicated with $5 \mathrm{mg}$ of oral diazepam on the night before and the morning of the surgery. All anesthetic blocks were performed by the same anesthesiologist, and general anesthesia was combined with the blockade of the group the patient was assigned to.

For the blockades, patients were placed on lateral decubitus, with the limb to be operated in the dependent position. In all cases, $0.5 \%$ chlorhexidine alcohol was used for antisepsis of the skin of the lumbar region, and the blocks were performed observing aseptic techniques, using fenestrated sterile fields and sterile gloves, besides cap and face mask. In the Epidural group, paramedian puncture was performed at the $L_{3}-L_{4}$ or $L_{4}-L_{5}$ space with a 18G Tuohy needle (Perifix ${ }^{\circledR}$, BBraun, Melsungen, Germany) using the loss of resistance technique. After identification of the epidural space, 10 to 15 $\mathrm{mL}$, according to the height of the patient and at the discretion of the anesthesiologist, of a solution of $0.5 \%$ ropivacaine were administered. Afterwards, a 20G multiorifice catheter was inserted 3 to $5 \mathrm{~cm}$ in the cephalad direction.

In the Lumbar group posterior lumbar plexus block was performed with an electrically isolated 10.2-cm Tuohy tip 18G needle (Contiplex ${ }^{\circledR}$, BBraun, Melsungen, Germany), according to the technique described by Capdevilla ${ }^{6}$. The lumbar plexus was identified by the motor response of the femoral quadriceps muscle and with the help of a peripheral nerve stimulator (Stimuplex Dig RC, BBraun, Melsungen, Germany). Initially, stimulation impulses were regulated with an intensity of $1.5 \mathrm{~mA}$, duration of $50 \mu \mathrm{sec}$, and frequency of $2 \mathrm{~Hz}$. After identifying muscle contractions, final positioning of the needle was based on the best response between 0.35 and $0.5 \mathrm{~mA}$. At that moment, $0.4 \mathrm{~mL} . \mathrm{kg}^{-1}$ of a solution of $0.5 \%$ ropivacaine was administered over one minute. Finally, a 20G multiorifice 
catheter was inserted cephalad, about 3 to $5 \mathrm{~cm}$ beyond the tip of the needle, into the psoas compartment.

After administration of the anesthetic solution, patients were placed on horizontal dorsal decubitus without evaluating the success or extension of the blockade. During the surgery, extra doses or infusion of ropivacaine through the catheter were not allowed. General anesthesia was induced with 20 $\mu \mathrm{g} . \mathrm{kg}^{-1}$ of alfentanil, $2 \mathrm{mg} . \mathrm{kg}^{-1}$ of propofol, and $1 \mathrm{mg} \cdot \mathrm{kg}^{-1}$ of succinylcholine. After tracheal intubation, general anesthesia was maintained with sevoflurane in a 1:1 mixture with oxygen and nitrous oxide under controlled mechanical ventilation, and ventilator parameters were adjusted to maintain normocapnia.

Difficulties performing both techniques were evaluated by counting the number of attempts and the time necessary to perform the blockade. Each change in needle direction was considered a new attempt without the need of a new puncture. The period from the first skin perforation until the catheter was inserted was considered the time to perform the blockade. The time necessary to secure the catheter was not considered, and the parameters used to assess the difficulty of the technique were the responsibility of an independent anesthesiologist not involved in the study.

Blood pressure (BP) both systolic and diastolic, and heart rate $(\mathrm{HR})$ were recorded upon arrival of the patient to the anesthetic induction room immediately before the blockade and skin incision at the beginning of the procedure, and one minute after skin incision. They were also recorded every 10 minutes until the end of the surgery.

Blood pressure and HR remained within 30\% above or below baseline readings at the anesthetic induction room. If systolic blood pressure or HR rose more than $30 \%$ of baseline levels, the fraction of expired sevoflurane was increased by $10 \%$, with a 3-minute interval between each change. If after three consecutive elevations in the fraction of expired sevoflurane the hemodynamic parameter did not return to the accepted variation range, intravenous alfentanil $10 \mu \mathrm{g} . \mathrm{kg}^{-1}$ was administered. Reduction in systolic BP were corrected with a $10 \%$ reduction in the fraction of expired sevoflurane, along with the intravenous administration of ephedrine $5 \mathrm{mg}$, at 3minute intervals until the range of $30 \%$ variation from baseline levels was achieved.

Crystalloids and colloids were used for hydration. Ringer's lactate was used for fasting replacement and hourly fluid needs, while intraoperative blood losses were replaced with $6 \%$ hydroxyethyl starch with a mean molecular weight of 130,000 Dalton and molar $\mathrm{C}_{2} / \mathrm{C}_{6}$ substitution of 0.4 (HES 130/ 0.4 ) at a 1:1 rate of intraoperative blood loss.

Hemodynamic effects secondary to the blockade were evaluated by the variation in the levels of $B P$ and $H R$, mean fraction of expired sevoflurane, and mean dose of ephedrine administered from the execution of the blockade until the end of the surgery. The efficacy of the nociceptive blockade produced by the anesthetic techniques tested was determined by comparing the variations in systolic, diastolic, and mean arterial pressure, as well as the HR, with the surgical incision. Other parameters used to evaluate the efficacy of the surgical blockade included mean fraction of expired sevoflurane and the need of blockade supplementation with alfentanil during the surgery.

The volume of intraoperative bleeding was estimated by weighing the surgical pads and measuring the volume of blood collected in the surgical field by aspiration, excluding the volume of NS used to wash the surgical wound. In the postoperative period, up to 48 hours after the surgery, bleeding was estimated by measuring the volume collected by the surgical drains. The number of packed-red blood cells $(300 \mathrm{~mL})$ transfused in the first 48 hours after the surgery was also recorded. Clinical criteria were used for the indication of blood transfusions. Hematocrit and hemoglobin levels were not used as transfusion triggers. The physician in charge of the intensive care unit decided whether to transfuse the patient based on the analysis of the volume of blood loss, associated diseases, and the postoperative clinical status of the patient.

A difference greater than $10 \%$ between the anesthetic techniques in the variation of mean arterial pressure after the incision was considered significant. For such and assuming a $3.5 \%$ variation with the epidural technique and standard deviation of $5.7 \%$ identified in a pilot study seven patients would be necessary in each group for an alpha of 0.05 and beta of 0.10 (90\% potency).

In the statistical analysis, continuous parameters were compared with the Student $t$ test. The Chi-square and Fisher's exact tests were used for the analysis of nominal nonparametric data. Parameters that did not show normal distribution were analyzed by non-parametric Mann-Whitney $U$ test. Analysis of Variance (ANOVA) for repeated tests (simple linear model) was used to evaluate whether only an effect of the observation time between both techniques evaluated on hemodynamic parameters (dependent parameters) after the blockades and during the surgery. After ANOVA, post hoc analysis (Bonferroni correction) was used to define possible intragroup differences and/or resulting from multiple comparisons.

When appropriate data are presented as means, medians, or proportions by category. Data were collected on Excel spreadsheet (Microsoft, v. XP, CA, USA), and the statistical analysis was carried out with SPSS for Windows (Statistical Package for the Social Sciences, v.13, Chicago, IL) and Stat View (SAS Institute, v. 5.0.1, Cary, NC, USA). To estimate the risk of type I error, a $p<0.05$ was used. In the analysis, patients were considered in the groups they were originally allocated therefore adopting the intention to treat principle.

\section{RESULTS}

During the study period, 42 patients were scheduled for THA. All patients who fulfilled the inclusion criteria agreed to 
participate in the study. One patient initially allocated in the Lumbar group was excluded due to a change in conduct during the surgery, undergoing acetabuloplasty. Thus, 20 patients were allocated in the Epidural group and submitted to statistical analysis, and 21 in the Lumbar group.

Patients included in both groups were similar regarding gender, age, weight, height, and physical status (Table I). Patients usually presented associated comorbidities, especially hypertension, but with equal distribution between groups. Hip arthrosis (63\%) was the most frequent preoperative diagnosis leading to surgery. The surgical technique (lateral or posterior approach) and the surgeon responsible for the procedure had similar distribution in both groups. The duration of the surgery was similar in both groups. However, in the Epidural group surgeries were more often on the right side $(\mathrm{p}=0.03)$.

The time required to perform the epidural block $(5.3 \pm 3.4$ minutes) was significantly lower than in the Lumbar group (7.6 \pm 2.8 minutes) $(p=0.02)$. On the other hand, both groups were similar regarding the number of attempts for final positioning of the needle. Multiple linear regression showed that in fact the anesthetic technique was an independent parameter of the time to perform the anesthetic blockade $(p=$ 0.01 ). When the analysis was stratified for elderly ( $>60$ years) and obese $(\mathrm{BMI}>25)$ individuals the time to perform the technique and the number of attempts did not differ between both groups (Table II).

The efficacy of the anesthetic blockade in the surgical incision was different between the study groups. In the Epidural group, variations in diastolic pressure $(p<0.01)$, MAP $(p<0.01)$, and the double product of systolic pressure and HR $(p<0.05)$ were lower (Table III). The mean fraction of expired sevoflurane during anesthesia confirms those results, since it was also lower in the Epidural group (Epidural $1.02 \pm 0.15 \%$ vs. Lumbar $1.34 \pm 0.34 \%, p<$ 0.0001). However, the need to supplement the blockades with alfentanil during surgery did not differ between the study groups.

After the blockade, BP levels differed between both groups. Mean arterial pressure was lower in the Epidural group 50, $60,70,80,90,110$, and 150 minutes after the blockade. However, ANOVA for repeated tests with Bonferroni correction demonstrated that MAP was lower in the Epidural group only 50,60 , and 70 minutes after the blockade $(p<0.003)$ (Figure 1). Similar analysis of the double product did not show differences between both groups during the observation period (Figure 2). The mean ephedrine consumption did not differ between the Epidural and Lumbar groups after the anesthetic blockade $(30.3 \pm 28.7 \mathrm{mg}$ and $17.6 \pm 18.5 \mathrm{mg}$, respectively).

Blood loss during the surgery was similar in both groups. Similarly, bleeding 24 and 48 hours after the surgery, as well as the total blood loss, did not differ between both groups (Table IV). Both groups had similar blood transfusion needs.
Table I - Demographic Characteristics and Functional Aspects of Patients Included in the Study, and Description of the Surgical Interventions

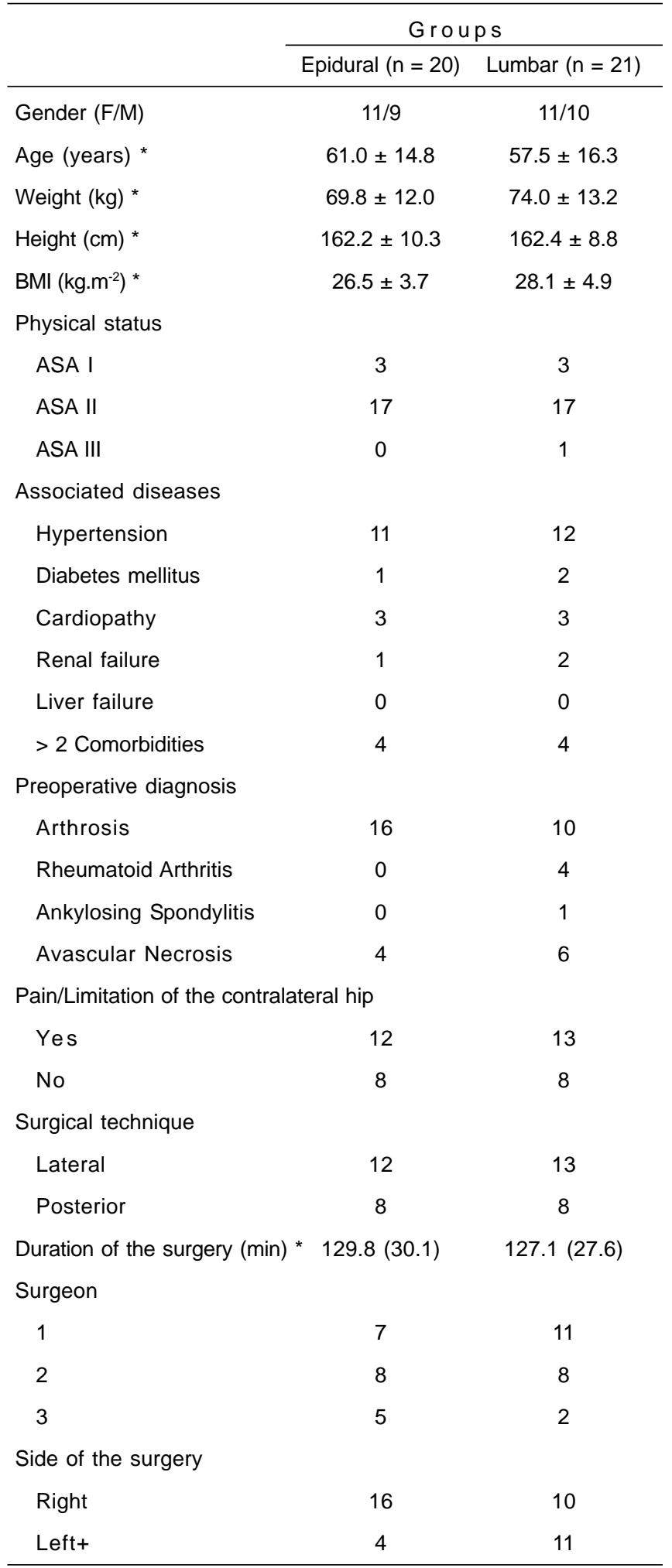

*Data expressed as Means (Standard Deviation) $+p=0.03$, side of the surgery $x$ groups 
Table II - Technical Difficulties Performing the Blockades

\begin{tabular}{lccc} 
& \multicolumn{2}{c}{ Groups } & \\
\cline { 2 - 2 } & \multicolumn{1}{c}{ Epidural } & Lumbar & $\mathrm{p}$ \\
\hline Time to perform the technique & $(\mathrm{min}){ }^{*}$ & & \\
All & $5.3(3.4)$ & $7.6(2.8)$ & 0.02 \\
Elderly & $6.4(3.9)$ & $6.4(2.0)$ & NS \\
Obese & $6.6(3.6)$ & $8.0(2.8)$ & NS
\end{tabular}

Number of attempts (n) +

$\begin{array}{lccc}\text { All } & 3(1-4) & 2(2-3) & \text { NS } \\ \text { Elderly } & 3.5(2-6) & 2(2-2.8) & \text { NS } \\ \text { Obese } & 4(2-6) & 3(2-3.3) & \text { NS }\end{array}$

Data expressed as: *Means (Standard Deviation); + median (interquartile range)

NS = non-significant
Table III - Percentage Variation of Hemodynamic Parameters after the Surgical Incision

\begin{tabular}{llcc}
\hline & \multicolumn{2}{c}{ Groups } & \\
\cline { 2 - 3 } Percentage variation & Epidural & Lumbar & p $^{*}$ \\
\hline Systolic blood pressure & $3.9(6.4)$ & $9.3(11.4)$ & NS \\
Diastolic blood pressure & $4.3(9.0)$ & $13.4(12.2)$ & 0.01 \\
Mean arterial pressure & $4.0(6.0)$ & $11.5(10.8)$ & $<0.01$ \\
Heart rate & $4.3(9.6)$ & $10.6(12.1)$ & NS \\
Double product & $8.7(15.2)$ & $21.3(22.2)$ & $<0.05$ \\
\hline
\end{tabular}

Data expressed as Means (Standard Deviation)

${ }^{*} \mathrm{NS}=$ non-significant; + Systolic blood pressure $\mathrm{x}$ heart rate

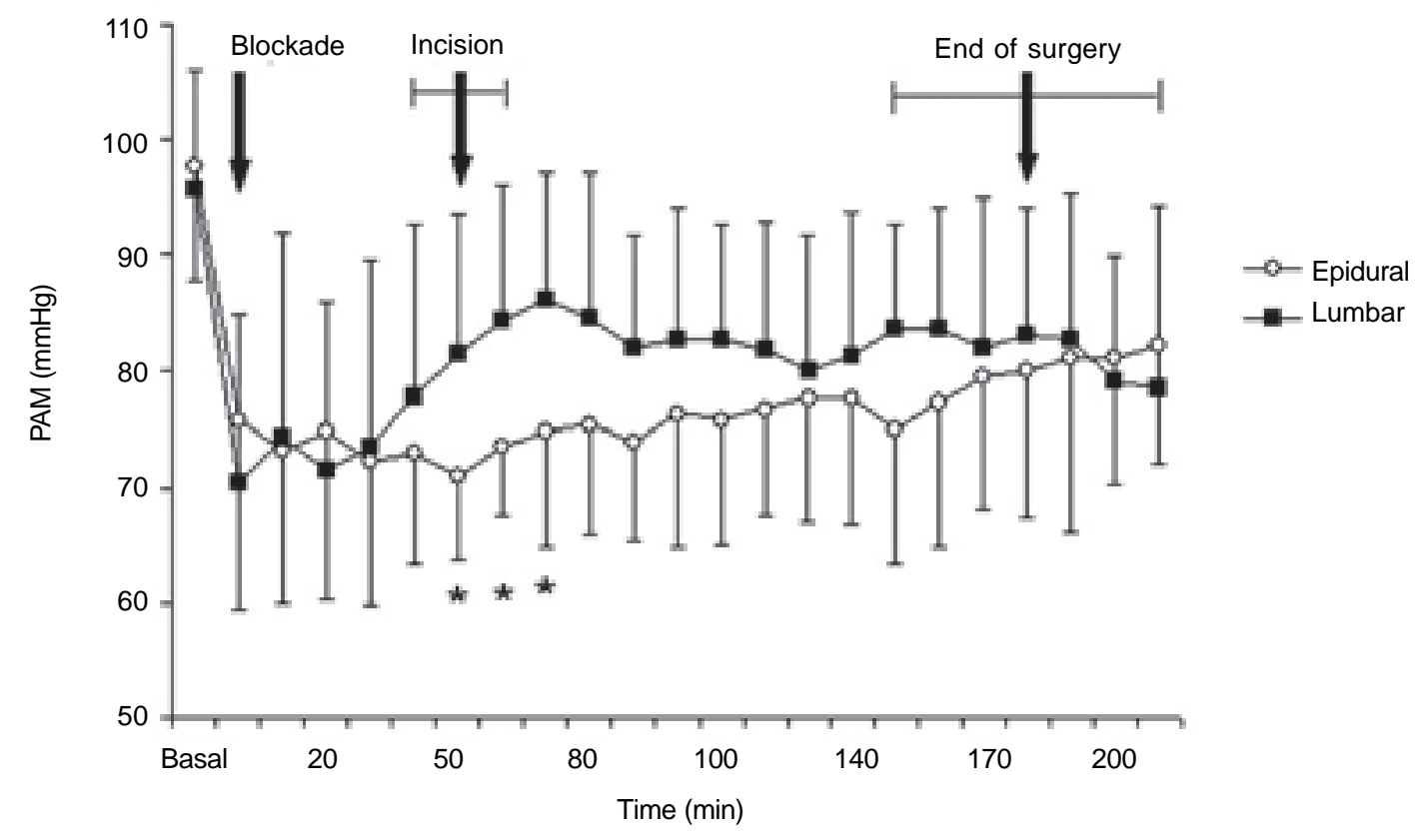

Figure 1 - Variation of the Mean Arterial Pressure after the Blockades and During the Surgery ANOVA for repeated tests with Bonferroni correction

${ }^{*} p<0.003$ 


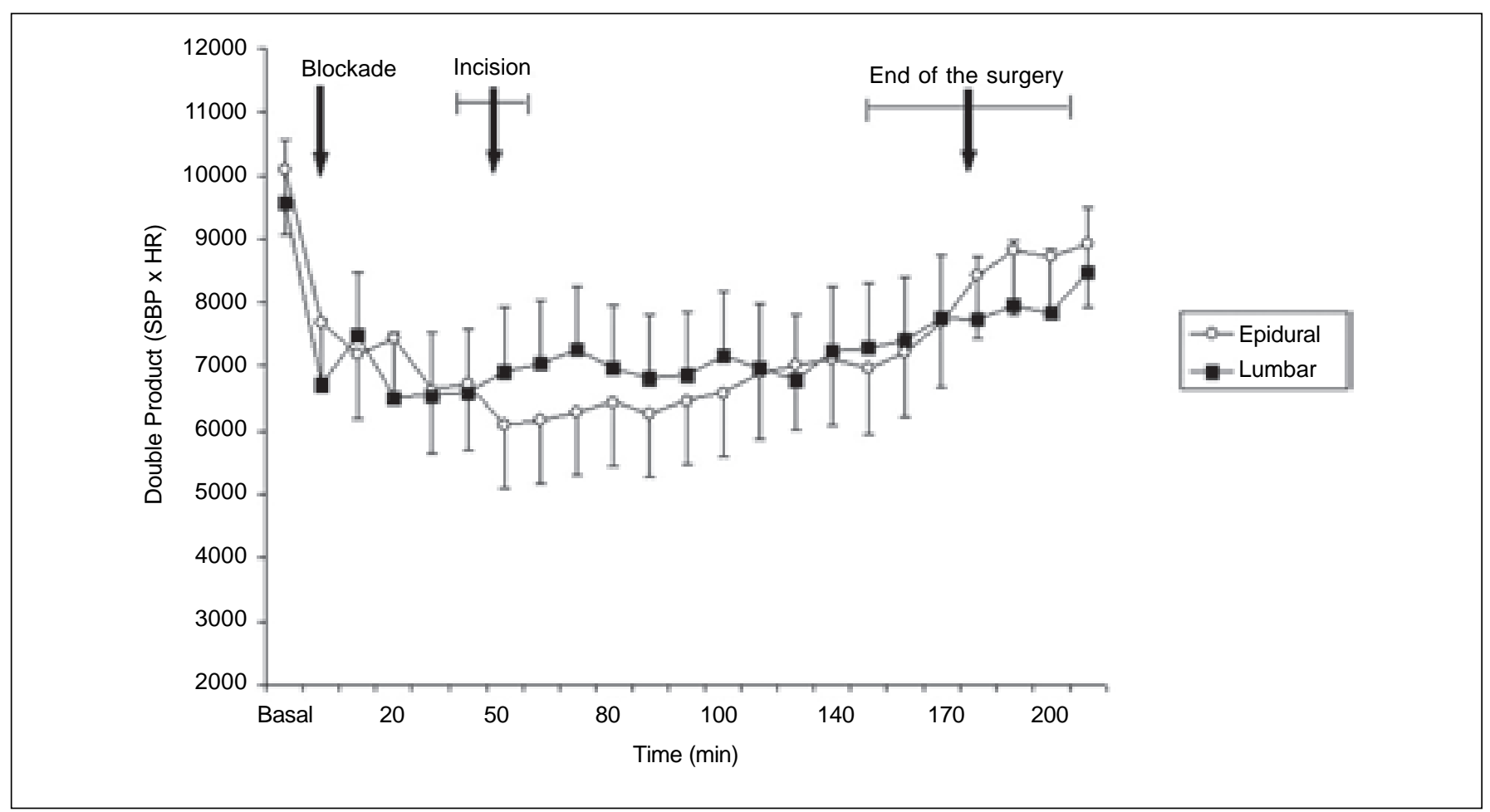

Figure 2 - Variation of the Double Product (DP) after the Blockades and During the Surgery Significant differences were not observed between the study groups

Table IV - Volume of intra- and postoperative blood loss

\begin{tabular}{lccc}
\hline & \multicolumn{2}{c}{ G r o u p } & \multicolumn{1}{c}{$\mathrm{p}^{*}$} \\
\cline { 2 - 3 } & Epidural & Lumbar & NS \\
Intraoperative bleeding $(\mathrm{mL})$ & $612.8(328.3)$ & $707.1(519.4)$ & $\mathrm{NS}$ \\
Bleeding in 24 hours $(\mathrm{mL})$ & $476.4(249.6)$ & $462.4(195.0)$ & NS \\
Bleeding in 48 hours $(\mathrm{mL})$ & $110.5(74.9)$ & $110.5(85.9)$ & NS \\
Total bleeding $(\mathrm{mL})$ & $1199.6(475.1)$ & $1280.0(635.6)$ & NS \\
Units transfused & $0.8(1.1)$ & $0.6(1.1)$ & \\
\hline
\end{tabular}

Data expressed as Means (Standard Deviation)

${ }^{*} \mathrm{NS}=$ non-significant

\section{DISCUSSION}

Epidural block promoted a more effective nociceptive blockade without hemodynamic instability when associated with general anesthesia. Both techniques were similar regarding the technical difficult and perioperative bleeding. Combined with general anesthesia, epidural block with $0.5 \%$ ropivacaine promoted more adequate blockade of the nociceptive stimulation produced by the surgical incision than posterior lumbar plexus block. Variations in systolic, diastolic and mean arterial pressure, HR, and double product were used as substitutes of blockade efficacy. Smaller variations in diastolic and mean arterial pressure, as well as the double product, observed in the epidural group, indicated more complete nerve block and also prevented exposing the patient to cardiovascular overload. This indicates that epidural block can exert a greater cardiac protector effect through better balance between myocardial oxygen delivery and requirements during the surgery.

The observation that the epidural block produce more complete nociceptive blockade was corroborated by the lower sevoflurane consumption during maintenance of general anesthesia. It is important to emphasize that the lower need of sevoflurane was not secondary to lower pressure levels in the Epidural group, since the consumption of ephedrine was similar in both groups after the blockade. Thus, the 
sevoflurane-sparing effect was in reality due to the greater effectivity of the epidural block.

It is possible that the greater variation in MAP and double product at the time of the surgical incision in patients in the Lumbar group can also be explained by possible failures in the territory of the lateral cutaneous nerve of the thigh in surgeries with the lateral approach or in the posterior approach by the fact that the incision reached the territory innervated by branches of the sacral plexus. The lack of evaluation of the extension of the lumbar plexus block after the initial dose to determine the success rate of the blockade and correlate it with the results observed can be considered a limitation of this study.

Unlike Chayen et al. ${ }^{9}$ and Vaghadia et al. ${ }^{10}$ who reported surgical anesthesia with lumbar plexus block as the single anesthetic technique, Chudinov et al. ${ }^{11}$ observed that the blockade produced enough analgesia for the surgery in only three out of 20 patients. Other authors share the opinion that posterior lumbar plexus block is not enough to provide adequate intraoperative analgesia in hip surgeries requiring the combination with general anesthesia or neuro axis block $^{12,13}$. Due to the important contribution of different branches of the sacral plexus for the innervation of the hip joint and musculature, as well as of the area of the skin incised in the posterior surgical approach ${ }^{14}$, lumbar plexus block by itself is not enough to cause complete interruption of nociceptive afferent stimuli originated from those structures. Sciatic nerve block should be added for adequate control of the pain originating in structures innervated by the sacral plexus ${ }^{15}$.

Usually, lumbar plexus block is used for postoperative analgesia in patients undergoing THA. In the present study the combination of lumbar plexus block and general anesthesia was idealized to evaluate the characteristics of the anesthesia provided by this combination and to compare it to that of the epidural block, another technique used for anesthesia and analgesia in THA and considered by many authors the gold-standard. Adding sciatic nerve block to lumbar plexus block promotes complete blockade of the nociceptive innervation of the hip, but the dose of local anesthetics is also increased considerably. Consequently, to avoid reaching toxic dose of the local anesthetic the concentration of the anesthetic administered in the blockade is reduced. The final result can be a reduction in the duration and quality of postoperative analgesia. It has been widely shown in the literature that pain relief after THA is promoted mainly by the lumbar plexus block and, in smaller scale, by the blockade of the sacral component. Continuous infusion of diluted local anesthetics in posterior lumbar plexus block produces analgesia of excellent quality after THA without the need to combine it with sciatic nerve block ${ }^{6}$. Thus, although complete anesthetic blockade is not achieved with the lumbar plexus block by itself it can be an alternative combined with another technique that promotes sacral plexus block, associated with general anesthesia or neuroaxis blockade (subarachnoid block is used more commonly) for surgical anesthesia or isolated for postoperative analgesia with little interference with hemodynamic stability.

During the surgery, MAP was significantly lower in the Epidural group between 50 and 70 minutes after the blockade. Since the skin was incised around the $50^{\text {th }}$ minute after the blockades (Figures 1 and 2) this difference was only observed in the beginning of the surgery. Besides, the difference was not secondary to a reduction in MAP in the Epidural group, but due to its elevation after the surgical incision in the Lumbar group. Before the incision, both groups showed similar behavior. As for the double product, despite the discrete increase after the incision in the Lumbar group, differences were not observed between both groups along the surgery, since the behavior of the systolic blood pressure and HR were similar in both groups.

Contrary to what was expected, due to the more extensive sympathetic blockade of the epidural block, the behavior of MAP and double product was similar to that observed in the Lumbar group. It is possible that the design of the study interfered with those results. The use of relatively small volumes of anesthetic for the epidural block could have contributed to limit the incidence of hypotension. Usually, hemodynamic changes secondary to peripheral nerve blocks are minimal ${ }^{3}$. In posterior lumbar plexus block, the sympathetic blockade is unilateral. But this technique is not devoid of risks. Even though it promotes unilateral and localized blockade, debilitated patients undergoing lumbar plexus block can develop hemodynamic instability. Besides, the combination of general anesthesia and posterior lumbar plexus block can produce significantly lower mean pressure levels than general anesthesia ${ }^{7}$. Hypotension can also develop due to the epidural dispersion of the local anesthetic ${ }^{16}$ or by inadequate positioning of the epineural catheter in the subarachnoid and epidural spaces ${ }^{6,17,18}$.

The choice of the anesthetic technique by the anesthesiologist is commonly affected by the experience and personal ability, and it is not systematically used in search of the best result ${ }^{1}$. The disadvantages of peripheral nerve blocks include greater patient turnover and higher equipment costs when compared to general anesthesia and neuroaxis block. The time required to perform the technique can be an important factor in the determination of the efficiency of operating rooms. Several anesthesiologists and surgeons report the impression that the peripheral nerve blocks demand more time, delaying the beginning of the surgery and increasing the occupancy time of the operating room. Different evidence contradicts this impression ${ }^{3,19}$. The results of the present study showed that the time required for neuroaxis and peripheral nerve blocks is similar. Despite the statistical difference observed, this did not have practical repercussions. The mean difference between both groups was of approximately two minutes. Besides, both techniques required similar number of attempts for the final positioning of 
the needle, corroborating the hypothesis that both demand similar technical ability by the anesthesiologist and time for execution. With training, both techniques will impose similar difficulties for the anesthesiologist. While other authors did not show differences in the time for conclusion of the posterior lumbar plexus block and subarachnoid block ${ }^{19}$, Türker et al. ${ }^{3}$ reported that continuous lumbar plexus block demanded less time and lower number of attempts than continuous epidural block.

Different authors have described similar times to those observed in the present study to perform lumbar plexus block $^{19-21}$. However, the majority of those authors did not defined clearly how they measured this time. On the other hand, Kaloul et al. ${ }^{22}$ using the same definition of the present study reported significantly longer time $(17.5 \pm 8.9$ minutes $)$ to perform the continuous lumbar plexus block.

During execution of the lumbar block the limiting step, and the one that required more time to be executed, seemed to be the insertion of the catheter. In several cases, the motor response of the quadriceps muscle was identified quite fast, but insertion of the epineural catheter required an extremely long time. However, this is only a subjective observation. The study design did not include the assessment of the time required for each step of both techniques.

Stratified evaluation of the technical difficulty of both blockades in elderly and obese patients was based on the hypothesis that the epidural puncture could be more difficult in those patient populations. However, contrary to the hypothesis of the author, both techniques were similar regarding the time required for the execution and number of attempts to position the needle. In fact, other studies have not demonstrated differences in difficulty, time to execute the technique, and failure index of neuro axis blocks between young and elderly individuals ${ }^{23}$. In reality, the greatest difficulty is related to patient positioning for the epidural block since most patients undergoing THA have arthrosis of the hips with limitation and pain during positioning to execute the technique. On the other hand, in lumbar plexus block identification of anatomical references can be difficult in obese patients, and in those with deformities of the spine puncture can be too close to the spinal column implicating on a higher risk of complications $^{6,16}$.

Perioperative bleeding is still an important problem in orthopedic surgeries, and therefore measures to prevent or decrease operative blood loss and the need of transfusions of allogeneic blood are necessary. Although neuroaxis blocks reduce intraoperative bleeding compared to general anesthesia ${ }^{24}$, evidence that peripheral nerve blocks have the same benefit is limited. Stevens et al. ${ }^{7}$ reported that lumbar plexus block promoted a significant reduction in bleeding during THA (22\%) and up to 48 hours after the surgery (45\%) when compared to general anesthesia. On the other hand, differences in the need of autologous transfusion did not differ and heterologous blood was not transfused ${ }^{7}$.
In the present study, lumbar plexus and epidural blocks when combined with general anesthesia had the same effect on blood loss during and after the surgery, and similar need of blood transfusions. Similarly, other authors did not observe differences in intraoperative blood losses and in the need of blood transfusions when continuous epidural block was compared to continuous lumbar plexus block or combined peripheral block ${ }^{3,25}$.

To conclude, nociceptive blockade was more effective with epidural block, which proved to be superior to posterior lumbar plexus block without associated hemodynamic instability. Although lumbar plexus block should not be used as the only anesthetic technique, and since both techniques had similar technical difficulties, hemodynamic stability during the surgery, and the volume of blood loss during and after hip arthroplasty this peripheral block can be used as an alternative combined with general anesthesia when epidural blockade is contraindicated.

\section{REFERÊNCIAS - REFERENCES}

01. Fischer HB, Simanski CJ - A procedure-specific systematic review and consensus recommendations for analgesia after total hip replacement. Anaesthesia, 2005; 60:1189-1202.

02. Singelyn FJ, Ferrant T, Malisse MF et al. - Effects of intravenous patient-controlled analgesia with morphine, continuous epidural analgesia, and continuous femoral nerve sheath block on rehabilitation after unilateral total-hip arthroplasty. Reg Anesth Pain Med, 2005;30:452-457.

03. Türker G, Uçkunkaya N, Yavasçaoglu B et al. - Comparison of the catheter-technique psoas compartment block and the epidural bock for analgesia in partial hip replacement surgery. Acta Anaesthesiol Scand, 2003;47:30-36.

04. Capdevila X, Barthelet $Y$, Biboulet $P$ et al. - Effects of perioperative analgesic technique on the surgical outcome and duration of rehabilitation after major knee surgery. Anesthesiology, 1999;91:8-15.

05. Horlocker TT, Wedel DJ - Anticoagulation and neuraxial block: historical perspective, anesthetic implications, and risk management. Reg Anesth Pain Med 1998;23(6 Suppl 2):129-134.

06. Capdevila X, Macaire P, Dadure C et al. - Continuous psoas compartment block for postoperative analgesia after total hip arthroplasty: new landmarks, technical guidelines, and clinical evaluation. Anesth Analg, 2002;94:1606-1613.

07. Stevens RD, Van Gessel E, Flory N et al. - Lumbar plexus block reduces pain and blood loss associated with total hip arthroplasty. Anesthesiology, 2000;93:115-121.

08. Horlocker TT - Peripheral nerve blocks-regional anesthesia for the new millennium. Reg Anesth Pain Med, 1998;23:237-240.

09. Chayen D, Nathan H, Chayen M - The psoas compartment block. Anesthesiology, 1976;45:95-99.

10. Vaghadia $H$, Kapnoudhis $P$, Jenkins LC et al. - Continuous lumbosacral block using a Touhy needle and catheter technique. Can J Anaesth, 1992;39:75-78.

11. Chudinov A, Berkenstadt $\mathrm{H}$, Salai $\mathrm{M}$ et al. - Continuous psoas compartment block for anesthesia and perioperative analgesia in patients with hip fractures. Reg Anesth Pain Med, 1999;24:563568.

12. Parkinson SK, Mueller JB, Little WL et al. - Extent of blockade with various approaches to the lumbar plexus. Anesth Analg, 1989; 68:243-248. 
13. Farny J, Girard M, Drolet P - Posterior approach to the lumbar plexus combined with a sciatic nerve block using lidocaine. Can J Anaesth, 1994;41:486-491.

14. Birnbaum K, Prescher A, Hessler S et al. - The sensory innervation of the hip joint-an anatomical study. Surg Radiol Anat, 1997;19:371-375.

15. Indelli PF, Grant SA, Nielsen K et al. - Regional anesthesia in hip surgery. Clin Orthop Relat Res, 2005;441:250-255.

16. Mannion S, O'Callaghan S, Walsh M et al. - In with the new, out with the old? Comparison of two approaches for psoas compartment block. Anesth Analg, 2005;101:259-264.

17. Litz RJ, Vicent $O$, Wiessner $D$ et al. - Misplacement of a psoas compartment catheter in the subarachnoid space. Reg Anesth Pain Med, 2004;29:60-64.

18. De Biasi P, Lupescu R, Burgun G et al. - Continuous lumbar plexus block: use of radiography to determine catheter tip location. Reg Anesth Pain Med, 2003;28:135-139.

19. Jankowski CJ, Hebl JR, Stuart MJ et al. - A comparison of psoas compartment block and spinal and general anesthesia for outpatient knee arthroscopy. Anesth Analg, 2003;97:1003-1009.

20. Destrube M, Guillou N, Orain C et al. - Bloc du plexus lombaire par voie posterieure realise sous anesthesie generale: etude descriptive de 93 cas. Ann Fr Anesth Reanim 2007;26:418422.

21. Morin AM, Kratz CD, Eberhart LH et al. - Postoperative analgesia and functional recovery after total-knee replacement: comparison of a continuous posterior lumbar plexus (psoas compartment) block, a continuous femoral nerve block, and the combination of a continuous femoral and sciatic nerve block. Reg Anesth Pain Med, 2005;30:434-445.

22. Kaloul I, Guay J, Cote C et al. - The posterior lumbar plexus (psoas compartment) block and the three-in-one femoral nerve block provide similar postoperative analgesia after total knee replacement. Can J Anaesth, 2004;51:45-51.

23. Tessler MJ, Kardash K, Wahba RM et al. - The performance of spinal anesthesia is marginally more difficult in the elderly. Reg Anesth Pain Med, 1999;24:126-130.

24. Guay $\mathrm{J}$ - The effect of neuraxial blocks on surgical blood loss and blood transfusion requirements: a meta-analysis. J Clin Anesth, 2006;18:124-128.

25. Davies AF, Segar EP, Murdoch J et al. - Epidural infusion or combined femoral and sciatic nerve blocks as perioperative analgesia for knee arthroplasty. Br J Anaesth, 2004;93:368-374.

\section{RESUMEN}

Duarte LTD, Beraldo PSS, Saraiva RA - Anestesia Epidural Lumbar o Bloqueo del Plexo Lumbar Combinados con la Anestesia General: Eficacia y Efectos Hemodinámicos en la Artroplastia Total de la Cadera.

JUSTIFICATIVA Y OBJETIVOS: La anestesia para la artroplastia total de la cadera (ATC), constituye un reto a causa de la edad avanzada y de las enfermedades asociadas a los pacientes. El objetivo del estudio, fue evaluar si el bloqueo del plexo lumbar combinado con la anestesia general, equivale a la anestesia epidural lumbar en cuanto a la eficacia del bloqueo nociceptivo, efectos hemodinámicos secundarios, dificultad en su ejecución e influencia en el sangramiento operatorio en pacientes sometidos a la ATC.

MÉTODO: Pacientes estado físico ASA I a III que fueron ubicados aleatoriamente en los grupos Epidural y Lumbar. En el grupo Epidural, se realizó la anestesia epidural lumbar continua con la ropivacaína a 0,5\% 10 a $15 \mathrm{~mL}$. En el grupo Lumbar, fue realizado el bloqueo del plexo lumbar por la vía posterior con ropivacaína a $0,5 \%$ 0,4 mL. $\mathrm{kg}^{-1}$. Todos los pacientes fueron sometidos a la anestesia general. Se estudiaron: la dificultad en la ejecución de los bloqueos, su eficacia y los efectos hemodinámicos secundarios.

RESULTADOS: Cuarenta y un pacientes fueron incluidos en el estudio. El tiempo para la ejecución del bloqueo epidural fue menor, pero el número de intentos en colocar la aguja fue similar en los dos grupos. El bloqueo epidural fue más eficaz. En el grupo Lumbar, se registró un aumento de la presión arterial diastólica y media (PAM) y en el doble producto. Después de la incisión, el consumo anestésico durante la operación fue mayor. Posteriormente al bloqueo, la PAM fue menor en los 50, 60 y 70 minutos después de la realización del bloqueo epidural. El sangramiento fue parecido en los dos grupos.

CONCLUSIONES: La técnica epidural promovió un bloqueo nociceptivo más eficaz sin asociarse a la inestabilidad hemodinámica, cuando se le combinó con la anestesia general. El bloqueo del plexo lumbar fue una técnica útil en combinación con la anestesia general cuando la anestesia epidural estuvo contraindicada. 